Multimedia Session Number \#2793

\title{
The Olympic Games: An Organizational Planning and Control Research Project
}

\author{
Keith M. Gardiner \\ Lehigh University, Center for Manufacturing Systems Engineering \\ 200 West Packer Avenue, Bethlehem, PA 18015, USA \\ 610/758-5070 Fax 610/758-6527 E-mail: kg03@Lehigh.edu
}

Introduction

Earlier papers ${ }^{1,2}$ introduced and described the concept of students as empowered employees in a "classroom factory." The factory mission is to achieve previously agreed collaborative research objectives, deliver final reports describing findings and conclusions all as a corollary to student learning. The primary purpose of the course, IE334, is to develop or improve the students' abilities, understanding and appreciation for the "soft skills" of organizational planning and control. It is recognized that "experiential learning," or "learning by doing," produces a superior classroom experience to uninvolved reading, listening or watching the wielding of chalk (unless this is done under the tutelage of the most exceptional, superb and captivating teachers!). This class usually enrolls between 40 and 50 students, mainly IE seniors, but with a scattering of juniors and individuals with other engineering majors; there are just occasionally one or two business and graduate students. The class is divided into teams that are required to develop a product in the form of a significant research report with an accompanying presentation to their peers. Each team is given responsibility for the specification of their own research objectives and deliverables within the pre-selected topic area. There are also subsidiary individual and team exercises designed to support the prescribed learning objectives.

Prior classes studied events on Mt. Everest in 1996 ("Into Thin Air," Krakauer ${ }^{3}$ ), the water and manufacturing problems at Woburn, MA ("A Civil Action," Harr"), and the tobacco industry ("Ashes to Ashes: America's Hundred-Year Cigarette War, the Public Health, and the Unabashed Triumph of Philip Morris," Kluger ${ }^{5}$ ). The analysis of the organizational aspects of the Olympic Games was selected as the topic area for the most recent fall offering. As a result of prior experience the 2001 "Olympic" class was managed, coordinated and directed somewhat differently and with efforts at greater control. Faculty assumed the role of plant manager, or CEO, and the class was put through rigorous procedures, exercises, presentations, grading, peer evaluations with corrective feedback relying upon the tools of organizational planning and control, or project management described in regular texts. ${ }^{6}$ For the most part students respond admirably in this elective class. This paper discusses briefly the key discoveries and findings out of twelve research reports relating to the Olympic Games, past, present and future. The subsidiary assignments and pedagogic methods are also reviewed. 


\section{Olympic Background}

The Olympic Games, and the associated "movement," or "Olympic family," arguably receive the greatest attention from the largest numbers of people from all countries and walks of life, and their media than perhaps any other events on the planet. They are in combination spectacular, newsworthy, exciting, gripping and brimming over with human interest. The phrase about "the thrill of victory and the agony of defeat ..." is well known. ${ }^{7}$ Huge interest, involvement of countless people, many companies, together with the more recent requirements for enormous amounts of cash have lead to frequent stories of corruption at all levels of the activities. At the bottom this starts with the national organization for an individual sport, money collection becomes a focus often to the detriment of the objectives for increasing participation in the activity and having more people have more "fun." Olympic medals must be won to secure more funding. At the sponsoring city, and national Olympic committee (NOC's) level there is need for millions to support a bid and then to build the necessary infrastructure. At the top of all this sits the International Olympic Committee (IOC), their president and executives, operating almost by fiat and hardly representative of anything but their own personal affiliations. It is not surprising that the US Congress held hearings to determine who did what and to whom, and were concerned about business practices, tax status and conflicts of interest. This has all been amply and excellently reported by Jennings, ${ }^{8}$ Lenskyj, ${ }^{9}$ and $\operatorname{Senn}^{10}$ in the three books that were selected as required reading for the 2001 course. Clearly, there are many aspects of the Olympic movement that provide fruitful ground for research into organizational planning and control, and the development of alternative practices and management structures.

\section{Course Objectives and Methods}

The course educational objectives aim for achieving an understanding of the organization of industrial engineering activity, i.e. the operation and management of a manufacturing system. There is a need to develop and demonstrate capability to analyze resource requirements, to solve problems, and the planing and implementing of projects, including the measurement and quality control aspects. A key concomitant is to develop an appreciation of the relationships between design, organization, plans, measurements, controls and results. An additional and more topical recent challenge has lead to the consideration of both ethical and global concerns as components of the problem set.

As this author has pointed out in prior papers all business and industrial activities are capable of being analyzed and understood as "manufacturing systems." Thus, accounting, banking, finance, insurance and transportation enterprises and other service industries all utilize resources aiming for the transformation of tangible and intangible goods (or materiel and data) for the realization of products and services that fulfill the needs of customers and thereby generate wealth. ${ }^{11}$ Likewise, design and management can be regarded as synonymous, they both involve allocating resources, assigning priorities and making choices of direction and details. ${ }^{12}$ Once these generic constructs are recognized it is feasible to interpret many exciting and interesting human endeavors as opportunities for problem solving project studies that engineering students may find different and stimulating.

A simple social typing test was used to identify the students by primary and secondary personality traits. ${ }^{13}$ The groupings comprise "Amiables," "Analyticals," Drivers," and "Expressives." This information coupled with biographic data resulting from the first assignment was used to assemble 
twelve balanced teams. Attention was paid to cultural and gender diversity, as was alphabetic position and three of the required books were assigned accordingly. These measures aimed to achieve good team collaboration and information sharing. There were both individual and team assignments; this ensures that no individual can lurk in the shelter of some excellent team members to secure an over-inflated grade, and also that good performers are not unduly penalized for being encumbered with slacking colleagues. Assignments are listed in Table 1.

\section{Table 1}

This is a class dealing with Organizational Planning \& Control (OPC), thus, the whole activity $\underline{A N D}$ every student must strive to demonstrate and embody exemplary organization, planning and control. Student contributions, including in-class discussions, questions, presentations and all written assignments will be observed to determine grades.

1. 300 word introduction with account of an OPC experience, plus personal bio., hobbies, interests, etc.

2. Executive report on the design, materials, resources, organization, processes of manufacturing and planning (realization/fulfillment), logistics, marketing and likely customer satisfaction to bring the product you will be given to the store, an accompanying presentation may be requested. (Items value about $\$ 2$ mainly from CVS or Kmart)

3. Teams will be established and an issue in manufacturing management must be evaluated with a report back to the class using a Power Point presentation explaining the issue(s), showing conclusions and recommendations with comprehensive references demonstrating your research discoveries. Presentations will be evaluated and graded by class members for content and delivery. A hardcopy two page executive summary is required for regular grading.

4. Each team must also prepare an analysis of specific selected aspects of the organizational planning and control of the Olympic industry, past, present and future, using assigned texts as just one source. There will be intermediate checkpoints, informal presentations, a final technical report and presentations at the end of the semester. Reports should include appropriate project plans with charts, estimates, analysis of budgets and schedules. Further requirements for this as signment will be derived as the project develops.

5. i) Individual assessment describing the contributions and role that you play in (3) and then (4), plus a commentary and interpretation on the effectiveness of the OPC ... How do you feel about the group performance, can it be improved, are interactions effective and is the project well managed? Recommend appropriate virtual bonus awards.

ii) Repeat at end of semester.

6. Individual problem-solving exercise involving organizational behavior with an ethics component - selected from among current issues. Develop diagrams showing authority-responsibility, reporting relationships, dependencies, and/or supply chain etc., and prepare a three page 'executive summary' defining your recommended potential OPC remedies.

7. Prepare a one-page news release describing the activities and accomplishments of the students in IE334.

8. All above evaluations will be added to the spreadsheet collating all class contributions and exercises together with an assessment for contribution s to class learning, participation, and a component scaled from the virtual bonus awards.

The individual assignments aim to have the students recognize organizational planning and control (OPC) as a pervasive activity implemented with variable effectiveness throughout human experience. They are also forced to become conscious of their own organizational environment, and of the necessity for measurements, controls, recognition, and reward together with mutual respect. Assignment 2 reminds them that this really is an engineering class requiring the deployment of individual analytical abilities and research. It forces an engagement with the whole organization of manufacturing or production engineering from concept to the shelf in the store. It also includes the important business and marketing considerations that urgently need integrating into engineering curricula. ${ }^{14}$ The "ethics" assignment 6 is unfortunately too easy to fulfill from the regular business news; in 2001 the case of Bayer and a drug recall problem was one option, ${ }^{15}$ 
others were selected from the Procter \& Gamble Annual Report and Proxy Statement and involved use of free-chlorine radicals in paper bleaching, executive compensation and other issues seeking shareholder's votes. ${ }^{16}$ The news release (\#7) forces reflection on what the student perceives may have been achieved during the course. This is also an unintended and entertaining opportunity for students to flatter faculty!

The teams completed assignment 3 by reviewing technical papers that had been produced by graduate students in a manufacturing management class the prior semester. This, not only brought out many issues germane to IE334, but also established team operating principles. The class were then presented with a request for proposals (RFP) from a range of possible Olympics research topics. Responses were then subject to negotiation to refine the topics and reduce redundancies. The next step required formal mission statements, objectives, goals, statements of deliverables and a timeline. The more vigorous teams attacked their assignments with enthusiasm, but, inevitably notwithstanding the OPC process one or two teams had a tendency to drift down fuzzy paths. Table 2 shows the titles of the final project reports.

Table 2

\begin{tabular}{|c|l|c|l|}
\hline Team & \multicolumn{1}{|c|}{ Topic } & Team & \multicolumn{1}{|c|}{ Topic } \\
\hline A & Advertising in the Olympic Games & G & Speed Climbing in the Olympics \\
\hline B & Olympic Rugby (plan to introduce) & H & London Summer Games 2012 (Swimming) \\
\hline C & Comparison of 4 NOC's operations & I & Replacement plan for the IOC \\
\hline D & The Athens Olympics: Now and in future & J & America's Games, NYC 2012 \\
\hline E & The Economic Olympic Committee & K & 2014 Winter Olympics, Santiago, Chile \\
\hline F & Olympic Games in Boston & L & An Olympic Security Commission \\
\hline
\end{tabular}

Olympic Study Results

Teams F (Boston), H (London), and J (New York) all showed project plans and bid justifications for their selected cities for 2012. The New York bid commended success as being a deserved legacy of September $11^{\text {th }}$ and relied heavily on extracts from the actual bid site on the web. The Boston bid showed originality in minimizing costs by using existing facilities and colleges in the area for arenas and distributed accommodations; unfortunately it was an implicit assumption that there was still time for the city to be placed on the list of US prospects. The London bid suffered a similar disadvantage, but started with a hypothesis that London had been awarded the 2012 Games and dealt solely with the issues associated with staging the swimming events in Oxford. Team K presented a novel idea for staging the Winter Games in the southern hemisphere during summer in the north, they were able to demonstrate Chile's capability for hosting the events.

Teams B (Rugby) and G (Extreme Speed Climbing) made good efforts portraying what needed to be done for a new sport to become an Olympic contest. They both accomplished appreciable research into regulatory matters for their respective sports and for meeting IOC requirements. There are many popular non-Olympic sports with ample potential that could displace some that may now seem strange or unusual and have only restricted specialist participation. Adding or removing sports is difficult within the Olympic bureaucracy. Team A reviewed interaction between the IOC and the major sponsors that advertise and promote their own products alongside the Olympics; their plan showed how a new sponsor should implement an "Olympic" relationship. 
Teams C, E, I and L all took different slants on organizational matters, but with overall conclusions sharing common threads. Team E took a major lead from Lenskyj' ${ }^{9}$ analysis and looked at legacies affecting former host cities. To avoid future fiscal disasters they proposed the formation of an Economic Olympic Committee (EOC). This committee would comprise well remunerated financial experts with responsibility for thoroughly reviewing the probity of all potential bid cities and counseling them on funding and budget practices. Team L did parallel work in proposing the development and implementation of an Olympic Security Commission, this would have oversight and review responsibilities to ensure that all arrangements and plans were adequate. The comparison of the Chinese, German, Japanese and Russian NOC's by Team C initially revealed vast differences in level of access to English language information, this restricted the scope; Senn ${ }^{10}$ was an important resource and 1936 news items added to a fine presentation.

Replacing the IOC with a totally different organization with distinct reporting requirements could reduce the perceived organizational problems, this was explored by Team I. The ultimate questions are "Who is in charge, to whom do they report and how are they appointed?" One may suggest the UN, the World Bank, or the World Trade Organization, but this is not their metier. Next, one could postulate the sponsors, or the athlete organizations assuming responsibility. Electing individuals from among the NOC's is another possibility, but NOC's are not uniformly democratic. In fact, NOC's in the countries with stronger democratic traditions appear to be largely appointed, or selected on the basis of hierarchical connections or nepotism. In contrast in autocratic regimes they are comprised of officials from sports bodies and government, an interesting difference. Group I skirted the philosophical issues and proposed a number of oversight committees, simultaneously reducing the power of the IOC president through an Executive Board. They also provided for athlete representation. This was a good beginning, but didn't address that interesting "first cause" question - who is it that has to implement this?

The next Summer Olympics are in Athens in 2004. Team D had access to good information and assembled the spectacular, but unlikely proposition, that Athens, if they do well in 2004 should become a permanent home of the Summer Olympics. This would eliminate contesting potential host cities and ensure the same climate for the participants year-to-year, but what of Beijing in 2008? They solved possible accommodation problems by the innovative use of cruise ships moored nearby. The accompanying graphics were in the best classical Greek tradition.

Team Assessments

The students inadvertently suffer an appreciable learning experience when they are assigned to teams that become dysfunctional. The way they "manage" and "organize" around this is an uncomfortable but powerful OPC lesson. Students in successful compatible teams know less of this. The one page student reports (\#5) and virtual bonus recommendations allow them to discuss this and reveal a lot about team morale. In prior classes teams have adjusted and the spread of bonus awards has flattened and reduced from the first exercise to the final one. ${ }^{2}$ In this class the reverse applied, after the first team assignment in 2001 the reports were very up-beat with a fair range of bonus award recommendations. Concluding reports were generally more critical with a greater bonus spread and some exceptional high and low fringe awards. High self-awards slightly distorted some averages. The figures show both the interim and final virtual bonus award recommendations for the classes in 2000, and 2001. There were 35 students in eight teams for 2000 and 47 in twelve for 2001. Student input was normalized to represent $\$ 10,000$ shared among four team members. A decline in morale can be inferred. In fall 2001 there seemed overall 
higher levels of stress than formerly, life seemed less fun and more business, possibly an aftermath of 9/11. Many priorities compete for attention as students wrap up their final year, including job interviews, and projects in required courses. Job opportunities were certainly somewhat reduced in 2001. After October there are many pressures, things are happening rapidly and there is a holiday interruption. Overall team performance deteriorated. Nevertheless there were teams with excellent functionality and output where the dynamics and responsiveness improved during the semester. Many students became more conscious of teaming interactions, and their activities in the course gave them distinctive and memorable experiences relating to the objectives.

Figure 1 and 2 - Virtual Bonus Awards, Dollars
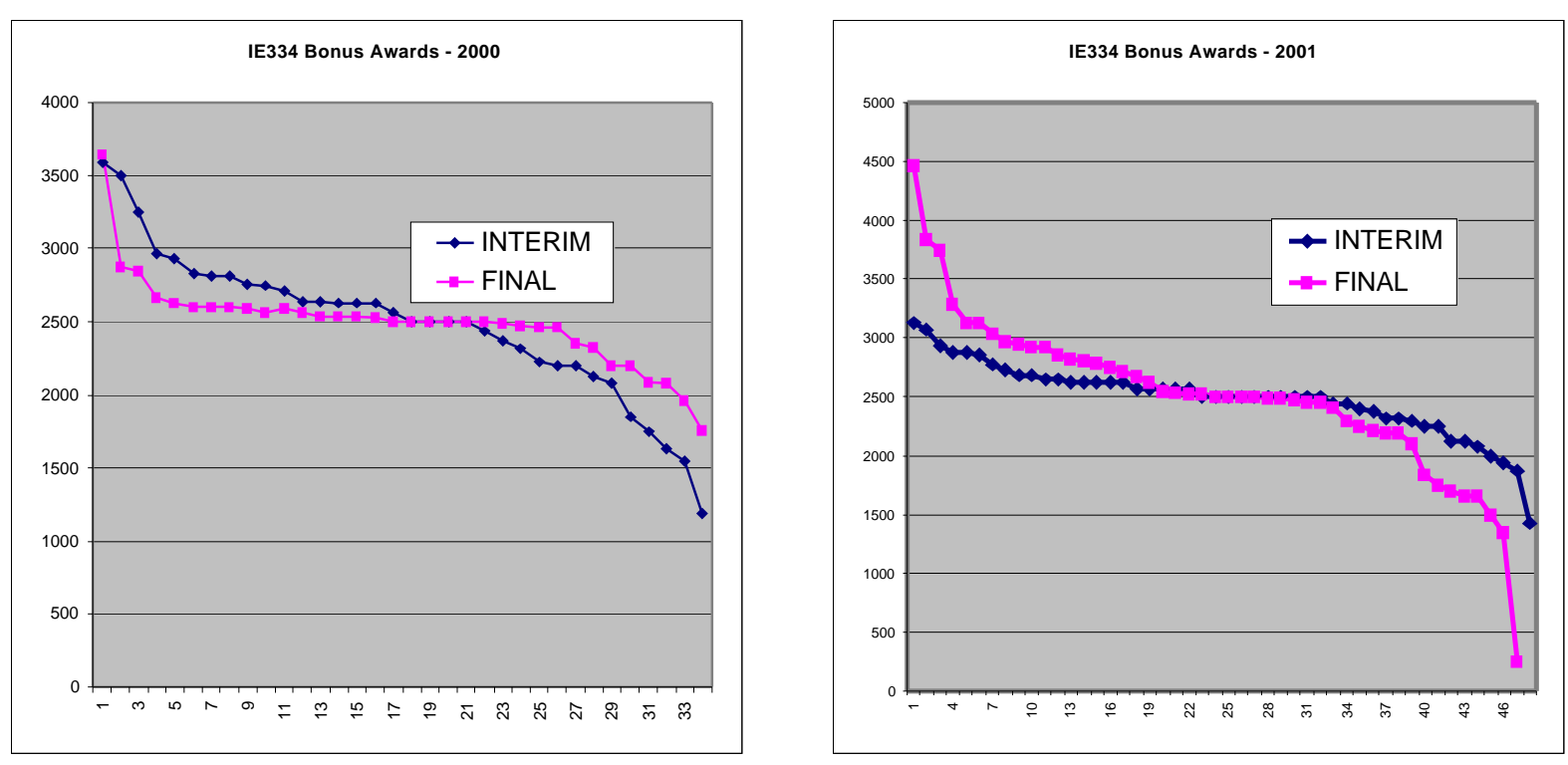

Conclusions

Discussions with students and anonymous surveys indicate that the procedures described have validity for achieving the course objectives and affording an effective learning experience. The students undoubtedly "learn by doing" and being responsible for designing and planning their activities. The students in 2001 were very enthusiastic and their presentations were excellent but the follow-up documentation was of lesser quality. Perhaps, the Olympic topics possessed greater ambiguity than those of prior years, output quality seemed affected. Research by undergraduates requires appreciable focus and time spent on advising to produce near publication-ready output. Calling for early preliminary draft reports and recommending changes was not received with great enthusiasm and did not adequately solve the problem noted in prior years. In the case of this class there was clear need to spend much more time with open in-class discussion of interpersonal behavior and team interactions. Reluctantly it appears that more emphatic management and direction appears to be essential (dictatorial and hierarchical?) in contrast to the somewhat laid back Deming-like approach which has been employed. ${ }^{17}$ It is intended to continue in this mode but with more coaching and the additional development of templates to improve final output. What next? It could again be the time for a study (and/or development) of comprehensive OPC for a past, present or future expedition around the World, or across Antarctica. Studies of the organization and planning for the fast food industry, or for the construction of Brunelleschi's dome also offer possibilities. 
The contributions, participation and suffering of numerous students are gratefully acknowledged.

\section{References}

1. Gardiner, K. M., “An Argument for Empowered Learning,” Proceedings, ASEE Mid -Atlantic Section Regional Conference, 1996.

2. Gardiner, K. M., "Organizational Planning and Control as an Un dergraduate Research Experience," ASEE Mid-Atlantic Region, Spring Meeting, April 21, 2001 (CD).

3. Krakauer, Jon, "Into Thin Air," Anchor, pp. 380, 1997.

4. Harr, J., "A Civil Action,” Vintage Books, pp. 502, 1996 (also a John Travolta movie).

5. Kluger, R., "Ashes to Ashes : America's Hundred-Year Cigarette War, the Public Health, and the Unabashed Triumph of Philip Morris," Vintage Books, pp. 848, 1997.

6. Lewis, J. P., "Fundamentals of Project Management," amacom, 1995. A text for the course.

7. Used all too frequently by sports commentators in the media, no attribution required.

8. Jennings, A., "The Great Olympic Swindle: When the World Wanted Its Games Back," Simon \& Schuster, 2000 (Required reading for one third of the class with surnames $A-G$ ).

9. Lenskyj, H. J., "Inside the Olympic Industry: Power, Politics and Activism," SUNY Press, 2000 (Required reading for one third of the class with surnames $H-M)$.

10. Senn, A. E., "Power, Politics and the Olympic Games," Human Kinetics, 1999 (N-Z).

11. Gardiner, K. M., Burnell, R., "Manufacturing - A Redefinition for the $21^{\text {st }}$ Century," 2000 Pacific Conf. on Manufacturing, Proc., Vol. 1, pp. 24-33, Lawrence Tech. Univ., 9/6-8/2000.

12. Gardiner, K. M., "Design: Organization and Measurement," Design Management, A Handbook of Issues and Methods, Part III - Corporate Approaches to Design Management, Chapter 17, pp. 156-166, Basil Blackwell, Oxford, 1990.

13. Prichard, A. K., Boeing Commercial Airplane Group, private communication, ackn. with appreciation, 1995.

14. "Manufacturing Education Plan: 1999 Critical Competency Gaps, Industry Updates Competency Gaps Among Newly Hired Engineering Graduates," SME, 1999.

15. "Drug's Removal Exposes Holes in Europe's Net," relates to Bayer - option for assignment \#6 http://www.nytimes.com/2001/08/22/business/22BAYE.html?searchpv=day01

16. Procter \& Gamble Proxy Statement - select for assignment \#6 from proposals 3, 4, 5 and http://www.pg.com/content/pdf/02_investor/financial_reports/proxy/2001_proxy_statement.pdf

17. Deming, W. E., recommended the abolition of fear from the workplace, see many quality texts. For example; Ross, J. E., “Total Quality Management,” St. Lucie Press, pp. 550, 1999.

\section{Biographical Information}

The author's involvement with the Olympic movement commenced with watching the 1948 London Games on black and white television. He has been engaged in cycling competition since 1950, and competed and trained with Olympic athletes in both the United Kingdom and North America. He still maintains a racing license and follows the sport eagerly. He has competed on various teams at badminton, cricket, field hockey, soccer and tennis. He is director of the Center for Manufacturing Systems Engineering and professor at Lehigh University, Bethlehem, PA. He spent 21 years with IBM in semiconductor manufacturing and then wi th the Corporate Manufacturing Technology Institute. Prior to this he worked on manufacturing methods for gas turbines with Rolls -Royce, and on the development of nuclear fuel elements with English Electric. He has degrees in metallurgy from the University of Manchester in England, and is a registered Professional Engineer (CA). He is a member of the College of Fellows of the Society of Manufacturing Engineers and currently serves on the SME board of directors, he was secretary-treasurer in 2000. E-mail: Keith.Gardiner@Lehigh.edu http://www.lehigh.edu/ inmse/gradprogram/profiles/kg03.html 